\title{
A pragmática no contexto da identificação de autoria de textos
}

\section{Jorilson Rodrigues}

Perito criminal federal, graduado em ciência da computação e bacharel em direito. Universidade de Brasília (UnB). Email: jorilson@apcf.org.br

\section{André Caricatti}

Perito criminal federal, mestre em ciência da computação. Universidade de Brasília (UnB).

Email: andrecaricatti@apcf.org.br

\section{Resumo}

Trata-se de artigo que estuda a viabilidade de identificar a autoria de textos a partir de elementos da linguística, mais precisamente da pragmática, considerando as inter-relações entre os elementos textuais e objetos externos, ligados a particularidades do "punho escritor", a exemplo dos fenômenos sociais em que o autor está inserido. A ideia é buscar a identidade textual a partir da análise do estilo, consideradas duas categorias discursivas: modalidade e avaliação.

\section{Palavras-chave}

Linguística computacional. Pragmática. Identificação de autoria.

\section{The pragmatic in the context of identification of authorship of texts}

\begin{abstract}
This article studies the feasibility of identifying the authorship of texts, from elements of linguistics, more precisely the pragmatic, considering the interrelationship between the textual and external objects, linked to features of the "wrist writer", like the social phenomena which the author is inserted in. The idea is to get the names from the textual analysis of style, taking into consideration two discursive categories: modality and evaluation.
\end{abstract}

\section{Keywords}

Computational linguistics. Pragmatic. Identification of authorship. 
A pragmática no contexto da identificação de autoria de textos

\section{INTRODUÇÃO}

Há basicamente duas maneiras de abordar o fenômeno comunicativo entre as pessoas: uma que privilegia os aspectos internos da língua e que leva em consideração sua estrutura, como, por exemplo, a fonologia, a sintaxe, os significados e interrelações, tratando, enfim, a língua como construto abstrato; e a outra, que procura abstrair-se desses parâmetros, para considerá-la como um fenômeno social, fruto de uma relação dialética entre a linguagem e a sociedade com seus valores, suas crenças no seio de lutas de poder, lutas, aliás, ideológicas e constitutivas das identidades de sujeitos sociais.

Apresenta-se a seguir um artigo baseado na segunda forma de considerar o fenômeno comunicativo. Trata-se de uma reflexão sobre a pragmática no que concerne à sua função constitutiva de identidades. Faz parte desta reflexão identificar, no bojo da teoria linguística, traços discursivos e pragmáticos que nos permitam apontar para diferentes identidades de produtores de texto.

Referir-se à pragmática é focalizar a ação. É conceber a linguagem em sua função protagonista do interagir. É reconhecer a força performativa da fala enquanto ato e é, portanto, um modo de enfocar o sujeito a fim de compreender os modos treinados, aprendidos, adquiridos nos sucessivos e múltiplos processos de socialização ao longo de sua vida. Todavia, é, sobretudo, uma maneira de observar como esse mesmo sujeito tem o poder de transformação e de crítica, rompendo os padrões responsivos previsíveis. A pragmática traz à tona esse sujeito real, uma vez que está voltada para a realidade multifacetada dos diversos usos da linguagem em dada sociedade. Nas palavras de Jacob Mey (2000, p.64), "pragmatics studies the use of language in the buman communication as determined by the conditions of society". (A pragmática estuda o uso da linguagem na comunicação humana observando as condições da sociedade.)
Para realizar a tarefa, apresenta-se, inicialmente, breve histórico da pragmática, de modo a destacar alguns conceitos relevantes, como contexto, atos de fala, força ilocucionária, entre outros. Em seguida, há uma reflexão sobre o conceito de identidade na modernidade tardia (termo utilizado por Giddens (2002) para se referir ao período atual repleto de mudança em escala global, de modo que os avanços na esfera da comunicação e nas novas formas da tecnologia da informação, somados à moldura cultural do pós-modernismo e à superação das categorias tempo e espaço, marcam essa nova fase da vida social). Destaca-se o conceito de identidade híbrida, segundo o qual o sujeito que costumeiramente é identificado por marcas linguístico-discursivas e pragmáticas previsíveis também é um sujeito-em-movimento e agente de rupturas com suas marcas discursivas de resistência. Cuida-se ainda da materialidade linguística da relação entre a pragmática e a constituição das identidades, uma vez que, de maneira mais específica, apresentam-se duas categorias discursivas/pragmáticas muito frutíferas para a análise do estilo/autoria que marcam diferentes identidades textuais - modalidade e avaliação. Por fim, destacam-se os caminhos e desdobramentos possíveis e futuros a partir do presente estudo.

\section{PRAGMÁTICA - VISÃO GERAL}

Ao ampliar a compreensão da linguagem para além do formalismo gramatical ou da relação símboloobjeto, incorporando a intenção do agente que emprega palavras para alcançar suas intenções, chega-se à perspectiva pragmática. Nesse contexto, consideram-se os usos linguísticos como atos que carregam propósitos, usos estes delineados por regras específicas das sociedades e culturas.

$\mathrm{O}$ indivíduo deve se submeter às condições e restrições impostas pelo meio em que coabita com seus pares, pois, somente acompanhando os sistemas linguísticos, os rituais e a cultura, as intenções alcançam êxito em sua porção social (OLIVEIRA, 2008). 
Os discursos são parte da "imensa fábrica social, na qual não apenas as palavras estão entrelaçadas, mas os atos e as vidas humanas" (MEY, 1993, p.194).

A pragmática surge quando as ciências da linguagem passam a tentar resolver problemas práticos, desdobrando os fenômenos linguísticos de acordo com diferentes visões e compreensões.

Caracterizada pelo estudo da linguagem como elemento de uso de pessoas em seus espaços, o termo serviu primeiro para Charles Morris, em 1938, tratar da "relação dos signos com seus intérpretes". Rudolf Carnap, contemporâneo e colega de Morris em Chicago, preferiu definir pragmática como o estudo da linguagem em relação aos seus falantes. Ambas as definições inserem o tema dentro da linguística que seria complementada pelo estudo das relações entres signos linguísticos, a sintaxe, bem como desses signos com os objetos a que se referem, a semântica.

Há os que defendam outra perspectiva, na qual a investigação da linguagem deve partir principalmente da consideração do seu uso concreto nos contextos sociais. Citam-se autores como Austin e sua teoria de atos de fala, a filosofia da linguagem ordinária de Gilbert Ryle ou os jogos de linguagem de Wittgenstein. Assim, a pragmática seria mais que meramente uma partição dentro dos estudos linguísticos, que então realizar-se-iam tendo como pressuposto a prática social concreta, com significados construídos nas interações entre pessoas, contextualizadas por elementos socioculturais, segundo as finalidades e efeitos esperados pelos interlocutores.

$\mathrm{Na}$ filosofia alemã, por sua vez, J.Habermas (Pragmática universal e Teoria da ação comunicativa) e K.O. Apel (Pragmática transcendental), inspirados no pragmatismo e na filosofia pragmática da linguagem, desenvolveram concepções de pragmática voltadas para a análise das condições de possibilidade da comunicação, de seus pressupostos e de suas implicações, inclusive nos campos da ética e da política (MARCONDES, 2008).

Haberland e Mey definem pragmática como a ciência do uso da linguagem nos contextos sociais, firmando uma relação utilitária entre linguagem e seu contexto de comunicação em que é empregada (OLIVEIRA, 2008).

Eis o conceito proposto por Crystal (1985, p. 240):

A pragmática é o estudo da linguagem do ponto de vista de seus usuários, particularmente das escolhas que eles fazem, das restrições que eles encontram ao usar a linguagem em interações sociais, e dos efeitos que o uso da linguagem, por parte desses usuários, têm sobre os outros participantes no ato da comunicação.

O filósofo H. P. Grice (1975) destacou que a cooperação é um elemento central para a pragmática, sugerindo como Princípio de Cooperação aquilo que as pessoas lançam mão para interagir, pretendendo que a conversação atinja seus objetivos. Logo, existiriam princípios gerais que condicionariam o reconhecimento por parte do ouvinte, que empregaria sua maneira particular de raciocinar e extrair o significado daquilo que o locutor diz. O Princípio de Cooperação contemplaria quatro pontos principais que conduziriam a conduta dos falantes nas interações:

a) máxima de qualidade: fale apenas sobre o que você possa fornecer evidência adequada;

b) máxima de relação: seja relevante;

c) máxima de modo: evite ambiguidades, seja breve e ordenado;

d) máxima de quantidade: informe apenas o necessário para a conversação, evitando excessos. 
A pragmática no contexto da identificação de autoria de textos

\section{CONTEXTO}

O contexto é fundamental para a pragmática. Ele é dinâmico, formando-se a cada momento pelas pessoas que interagem. É abstrato, sujeito a fatores do mundo sociocultural, externo aos interlocutores, sua capacidade para formação de conceitos e suas respectivas emoções.

Torna-se necessário ao falante saber como o ouvinte usualmente estabelece sua compreensão, a fim de evitar desentendimentos e aproximando as crenças que se prentendia transmitir com a informação introjetada (OLIVEIRA, 2008).

\section{A QUESTÃO DAS IDENTIDADES}

A questão da identidade e da diferença está, hoje, no centro da teoria social e da prática política, e a base da discussão sobre essa questão "está na tensão entre perspectivas essencialistas e perspectivas não essencialistas sobre identidade" (WOODWARD, apud SILVA, 2000, p. 12). Uma definição essencialista procura identificar nos grupos sociais aquilo que eles possuem de universal, de igual (a essência), aquilo que não se altera durante o tempo e que distingue um grupo de outro. Porém, em razão dos novos movimentos sociais, o caráter fixo da identidade tem sido questionado. Uma definição não essencialista de identidade, entretanto, relaciona esse conceito à questão da diferença, ou seja, nessa concepção, o que se enfatiza é que a identidade não é essência fixa, não é permanente nem vale para todas as épocas. Ao contrário, é uma construção, um efeito, é instável ou fluida, é contraditória, inacabada e fragmentada (SILVA, 2002).

As identidades se formam e são atravessadas pelas posições construídas historicamente nos discursos; são constituídas heterogeneamente pelos efeitos das diversas posições de sujeito (CHOULIARAKI; FAIRCLOUGH, 1999, p. 25). Isso leva a entender que as mesmas pessoas, dependendo do lugar que ocupam nas práticas discursivas, posicionam-se de forma múltipla, através de identidades diferentes e contraditórias. Os autores são, portanto, "uma multiplicidade desconcertante e cambiante de identidades possíveis" (HALL, 2001, p.14).

Conforme Hall (2001), a identidade é um ato performativo em que os indivíduos constroem o mundo e a si próprios. Butler (1990), em sua teorização sobre as identidades de gênero, compartilha a noção de uma identidade não essencial e performática de Hall. Como esse autor destaca, mostrar a natureza da identidade como algo não essencial não diminui em nada a sua eficácia discursiva, material ou política. A identidade não é um conceito essencialista e estável, mas, sim, relacional e instável, e que permite aos indivíduos constituírem-se multiplamente. Portanto, compreender a identidade como um ato performativo é compreender os indivíduos não com base em alguma essência, mas como sujeitos que se constituem nos discursos e as identidades como construídas discursivamente nos eventos discursivos. Quem nós somos depende dos eventos discursivos dos quais participamos. Segundo Hall (2001, p.116), a identidade trata-se sempre de um "sujeito-em-processo", uma constituição que nunca cessa, por isso há sempre possibilidade de quebra e de mudança nas representações discursivas, o que ocorre no discurso.

É importante salientar que tanto a identidade quanto a diferença são produtos culturais e sociais, além de criações linguísticas, e são constituídas por atos de linguagem. A natureza da linguagem que usamos, consequentemente, exerce implicações nos modos como as subjetividades são construídas e produzidas, acarretando novas formas de se perceber e de perceber o outro.

Ao usarem a linguagem, acreditamos que os indivíduos não reproduzem apenas as relações de poder, podem refletir posições de resistência ao poder, de emancipação, de diferenças, de vozes alheias que incorporam de outros discursos e ideologias, ao mesmo tempo que podem também se reposiciocionar, transformando suas identidades e podendo, assim, agir sobre a sua realidade social. 
Para tanto, necessário se faz discutir a relação da/ $\mathrm{s}$ identidade/s com a linguagem, que é fundamental, pois "ao significar, nos significamos" (ORLANDI, apud SIGNORINI,1998, p. 205).

\section{A LINGUAGEM NA CONSTITUIÇÃO DAS IDENTIDADES}

A linguagem ocupa uma posição central na constituição da/s identidade/s do indivíduo, uma vez que esta/s se constrói(oem) na língua e por meio dela, não existindo de maneira fixa e anterior a ela. Por estar sempre em evolução em uma rede de relações que se cruzam e nos definem ou nos posicionam na realidade, conceituar identidade é considerado tarefa difícil. Como afirma Orlandi (apud SIGNORINI,1998, p. 204), identidade é um movimento na história que não resulta de aprendizagem, mas se refere a posições que se constituem em redes de filiações históricas fazendo com que o sujeito, ao significar, também se signifique.

Hall (2001, p. 222) indica que

ao invés de pensarmos em identidade como um fato já concluído, devemos pensar como uma produção que nunca está completa, que está sempre em processo, sempre constituída dentro e não fora da representação,

portanto, constantemente reposicionada. Devemos considerar nossas identidades como construídas em nossas práticas discursivas com o outro, pois as pessoas têm suas identidades construídas de acordo com o modo pelo qual se vinculam a um discurso. A identidade é, pois, uma construção social, fruto da interação. E as identidades sociais de classe, gênero, raça, idade, profissão etc. são simultaneamente exercidas pelas mesmas pessoas.

Como observa Hall (2001), os "sujeitos são produtos de várias histórias e culturas interconectadas, pertencem a uma e ao mesmo tempo a várias casas", e reforça tal afirmação usando a expressão "indivíduo híbrido", também presente em Bhabha (1998). Esse autor define "indivíduo híbrido" como aquele que pertence a dois ou mais mundos ao mesmo tempo. Nesse sentido é que se pode dizer que é um sujeito em fluxo ou em processo, mutante ou proteiforme como sugere Rajagopalan (apud SIGNORINI,1998, p. 41-42). Logo, o sujeito assume identidades diferentes transformadas continuamente.

A identidade deve ser pensada em termos de evento e estrutura. A estrutura é o reconhecimento ou o consenso sobre determinada posição de sujeito, o que Gramsci considerou hegemonia (hegemonia, termo cunhado por Gramsci, é concebida como a organização do consentimento, pela qual se constroem formas subordinadas de consciência, sem recurso à violência (física) ou à coerção) e Bourdieu, doxa (doxa é o conjunto de crenças que constituem o senso comum, por serem concebidas como dadas e naturais e, por isso, não são questionadas). Já o evento, quando relacionado à identidade, pode trazer o germe da inovação e da contestação da hegemonia vigente, o que Bhabha estabelece como efeito de contingência ou performatividade.

Diante dessas acepções sobre identidade, verificase que evento e estrutura estão presentes nas sociedades contemporâneas de forma que os eventos contestatórios são sufocados e destituídos de valor por aqueles que representam discursos hegemônicos. Tal negociação entre estrutura e evento não é algo simples; pelo contrário, a complexidade e as pressões sociais implicadas permitem pouca percepção de mudança na estrutura social.

Chouliaraki e Fairclough (1999) defendem que a modernidade tardia mina identidades individuais e coletivas; portanto, lutas para a construção de identidades no discurso são um traço saliente da vida social nessa fase da modernidade. Harvey (2000) contribui para a sustentação dessa defesa, ao identificar, segundo Chouliaraki e Fairclough (1999, p. 78), dois tipos de reação às mudanças ocorridas na modernidade tardia: uma exploração das múltiplas possibilidades geradas, por exemplo, 
no cruzamento de fronteiras e no hibridismo de práticas; e uma reação mais defensiva que tenta restabelecer identidades individuais e coletivas e que envolve tematização da nação, da religião, da comunidade e da família em formas de novos movimentos sociais.

Questões de luta pela identidade são parcialmente questões de discurso. Uma das funções da ciência crítica é tentar desvelar aspectos negativos da "nova ordem mundial" hegemônica e mostrar que podem ser mudados pela agência humana, dado que não são naturais, mas são, pelo menos em parte, o resultado de estratégias particulares engendradas por meio de decisões políticas de acordo com interesses determinados.

\section{MATERIALIDADE LINGUÍSTICA}

De acordo com Bakhtin (1992), a materialidade linguística traz em seu cerne a ideologia e, em decorrência desse pressuposto, a linguagem não pode ser apartada das formas concretas de interação social, ou seja, a comunicação não pode ser separada de sua base material, que envolve sujeitos reais em contextos reais que se relacionam no interior de uma cultura e de um panorama sociopolítico e econômico. Os discursos não apenas refletem ou representam entidades e relações sociais (foco na reprodução social), mas também contribuem para sua construção (foco na transformação social).

Pode-se então observar que enquanto o foco sobre o sujeito e o sentido não perpassam pelo caminho da historicidade e da ideologia, esse conceitos ficam centrados na ideia da existência absoluta e originária de um 'EU' e de um sentido a priori. A partir do momento que passam a integrar um novo paradigma que contempla a interação com o outro (TU), sob uma ótica dialógica no bojo de um cenário mais amplo, o escopo teórico se abre deslocando o conceito do sujeito e do sentido, que perdem sua centralidade, estabilidade e seu caráter homogêneo e passam a se caracterizarem pela heterogeneidade, pelas redes de crenças e valores, pelas diferentes vozes sociais.
Fazer sentido depende não só do que está explícito em um texto, mas também do que está implícito - o que é assumido na interlocução. De acordo com a Fairclough (2003), o que está 'dito' em um texto sempre pressupõe o que "não está dito" e parte da análise dos textos é tentar identificar o que está pressuposto. Quando diferentes discursos entram em conflito, o que está sendo realmente contestado é o poder desses sistemas semânticos pré-construídos, um poder performativo para sustentar ou reafirmar o mundo em sua imagem. É importante ressaltar ainda que diferentes discursos podem usar as mesmas palavras, mas são as relações semânticas e as marcas de identidades estabelecidas que dirão quais são essas diferenças de sentido.

Uma forma de verificar isso é observar, por exemplo, nas colocações, os padrões de coocorrência das palavras nos textos, palavras que precedem ou seguem as palavras-chaves e verificar as modificações desses padrões ao longo do tempo, ou ainda, por exemplo, como a escolha das palavras pode nos falar muito sobre as posições que os sujeitos produtores do textos assumem em sua autoria.

Com relação ao último aspecto, chamamos a atenção para o âmbito do vocabulário no qual estão implicados processos de lexicalização e de significação do mundo, levando-se em conta o momento histórico e os grupos sociais envolvidos. A relexicalização dos domínios das experiências pode ter significado político e ideológico, uma vez que os sentidos das palavras podem estar inseridos em lutas pelo poder. A metáfora é outro aspecto do vocabulário que possui implicações ideológicas nos processos das seleções estratégicas. Escolher nomear uma manifestação pública, em uma reportagem de jornal, por exemplo, de "os baderneiros" ou " os lutadores de direito" trava uma relação bastante distinta e nos mostra a posição política que o produtor do texto está assumindo.

Conceber o discurso como parte da prática social implica entender o discurso como um MODO DE 
AÇÃO sobre a constituição do mundo, como um MODO DE REPRESENTAÇÃO desse mundo e ainda como MODO DE IDENTIFICAÇÃO dos sujeitos que interagem no mundo.

Neste artigo interessa focalizar as relações presentes entre o modo de AÇÃO e o de IDENTIFICAÇÃO. Para tal, apresentamos duas categorias linguísticas que consideramos relevantes para este estudo: modalidade e avaliação.

A modalidade e a avaliação, segundo Fairclough (2003), dizem respeito a como os autores se comprometem com eles mesmos em relação ao que é 'verdade' e ao que é necessário (modalidade) e, ainda, em relação ao que é desejável ou não, bom ou ruim (avaliação). Para o autor, esse comprometimento é uma parte importante de como os produtores identificam a si mesmos em suas identidades texturizadas.

\section{MODALIDADE}

Diferentes autores apresentam suas definições para a categoria da modalidade (quadro 1).

A modalidade é vista como parte da atividade ilocucionária, tendo em vista que o foco está na atitude do falante perante o enunciado produzido em dado contexto social discursivo (KOCH, 1999). Os diferentes empregos das modalidades são motivados pelo "jogo da produção e do reconhecimento das intenções do falante" $(\mathrm{KOCH}$, 1999, p.75).

Não se trata de uma relação fechada entre o self e o mundo. Trata-se, sobretudo, de identidades texturizadas, tanto em nível pessoal (personalidade) quanto social. $\mathrm{O}$ modo como você se compromete com o que você fala (ação) diz muito sobre quem você é (identidade).

As escolhas de modalidade nos textos podem ser vistas como partes do processo da autoidentidade texturizada e são significativas não só em termos de identificação, mas também em termos de ação (relações sociais da ação) e de representação todos dialeticamente relacionados.

É importante ressaltar que há limites sociais nas escolhas de modalidade que vão além de relações sociais de um texto particular. A quem é "dado" socialmente o poder de dizer o que e de que maneira? E aqui entramos no âmbito das predições.

\section{TIPOS DE TROCAS, FUNÇÕES DE FALA E TIPOS DE MODALIDADE}

- Troca de conhecimento (modalidade epistêmica):

- declarações: autor se compromete com "a verdade". Afirma, modaliza ou nega;

\section{QUADRO 1}

\section{Definições de modalidade}

\section{Autores}

Halliday (1994)

Verschueren (1999)

Hodge e Kress

\section{Conceitos de modalidade}

Julgamento do falante acerca das probabilidades ou obrigações envolvidas no que ele diz.

Envolve os principais modos nos quais as atitudes podem ser expressas junto à 'pura' referência (factualidade, níveis de certeza e de dúvida, necessidade, possibilidade).

Postura que o falante toma junto às representações, seu nível de afinidade com elas. 
- questões: autor realça o compromisso de "verdade" dos outros: não modalizada positiva, modalidade, não modalizada negativa.

- Troca de atividade:

- demanda: autor se compromete com a obrigação/necessidade: ordena, modaliza e proíbe;

- oferta: autor se compromete com o ato: assume, modaliza e recusa.

Sob esta ótica, há diferentes níveis de comprometimento com a verdade e com a necessidade: Verdade (certamente, provavelmente, possivelmente)/ Obrigação/necessidade (exigido, suposto, permitido). Essa visão vai, enfim, além dos marcadores explícitos de modalização.

\section{MARCADORES DE MODALIZAÇÃO}

O autor pode estabelecer diferentes níveis de compromisso por meio de sua fala / seu texto. O tipo de compromisso que ele faz se baseia na intersecção entre modalidade e outras categorias nas orações, incluindo funções de fala e modo gramatical, pessoa e o tipo de processo. Os marcadores de modalização são enumerados da forma em que se encontram no quadro 2 .

\section{AVALIAÇÃO E VALORES}

Avaliação está relacionada aos valores dos autores. Tais valores são apresentados nos textos, o que é parte constituiva de suas identidades, por modos mais ou menos implícitos ou explícitos. Diz respeito ao comprometimento dos sujeitos com seus próprios valores.

As categorias podem ser assim descritas (FAIRCLOUGH, 2003): Declarações avaliativas/ declarações com modalidade deôntica/ declarações com verbos de processos mentais afetivos/ suposições de valor.

\section{DECLARAÇÕES AVALIATIVAS}

São declarações sobre o que é desejável ou não desejável, o que é bom e o que é ruim. São realizadas como processos relacionais em que o elemento avaliativo é um atributo (adjetivo ou frase nominal). Além disso, o elemento avaliativo pode ser também expresso por verbo ou advérbios avaliativos ou até mesmo por exclamações.

\section{DECLARAÇÕES COM MODALIDADE DEÔNTICA (OBRIGAÇÃO) OU DE PROCESSOS MENTAIS AFETIVOS}

Modalidade deôntica está relacionada à avaliação, pois são declarações de obrigação, do que é desejável ou uma boa coisa a ser feita. Inclui os processos mentais afetivos (gostar/odiar), que são também chamados de avaliações afetivas. $\mathrm{Na}$ realidade, são avaliações subjetivamente marcadas.

\section{VALORES SUPOSTOS}

Há casos sem os marcadores relativamente transparentes de avaliação, em que os valores estão

\section{QUADRO 2}

\section{Marcadores de modalização}

Verbos modais, advérbios modais, adjetivos particípios, orações de processos mentais (eu acho).

Adjetivos modais (possível).

Verbos do tipo 'parecer'.

Advérbios do tipo: de fato, obviamente, evidentemente, sempre, usualmente...

Entonação e outros aspectos orais. 
mais subjacentes no sentido mais profundo do texto. Na verdade, os valores supostos dependem do sistema de valores implícitos existentes entre autor e intérprete. São, enfim, marcadamente de ordem social e ideológica.

\section{CONSIDERAÇÕES FINAIS}

O estudo apontou duas maneiras de abordar o fenômeno comunicativo entre as pessoas: uma que privilegia os aspectos internos da língua e que leva em consideração sua estrutura; e a outra que procura abstrair-se desses parâmetros, para considerá-la como um fenômeno social, fruto de uma relação dialética entre a linguagem e a sociedade com seus valores, suas crenças e lutas, as quais são constitutivas das identidades de sujeitos sociais.

$\mathrm{O}$ artigo privilegiou as referências à pragmática como ação, de modo a enfocar o sujeito e compreender os modos treinados, aprendidos, adquiridos nos sucessivos e múltiplos processos de socialização. O poder de transformação e de crítica interessou sobremaneira, na medida em que é responsável pelo rompimento de padrões responsivos previsíveis. Com isso, um momento importante se torna plausível, ou seja, o sujeito real surge, quando então é possível estudá-lo.

Os conceitos de contexto, atos de fala, força ilocucionária foram apresentados e discutidos, propiciando a reflexão sobre o conceito de identidade na modernidade tardia destacando o conceito de identidade híbrida. A partir desse contexto, destacou-se que o sujeito é identificado por marcas linguístico-discursivas e pragmáticas previsíveis, também é o sujeito-em-movimento e agente de rupturas com suas marcas discursivas de resistência.

$\mathrm{O}$ artigo defendeu que a materialidade linguística da relação entre a pragmática e a constituição das identidades se apresenta com categorias discursivas/pragmáticas muito frutíferas para a análise do estilo/autoria que marcam diferentes identidades textuais - modalidade e avaliação.
O capítulo 2 tratou da pragmática, definindo que no contexto deste artigo interessa observar a relação dos signos com seus intérpretes. Justamente o conceito que mais se aproxima dos aspectos relativos à prática social concreta, com significados construídos nas interações entre pessoas, contextualizadas por elementos socioculturais, segundo as finalidades e efeitos esperados pelos interlocutores, ou seja, traz a carga subjetiva tão importante para estudar a identidade do autor.

A questão da identidade, por estar no centro da teoria social e da prática política, surgiu com base da discussão, logo, as identidades se formam e são atravessadas pelas posições de sujeitos que são construídas historicamente nos discursos. Afinal, é necessário interagir com outros membros da sociedade, de maneira diferente, porém, o autor guardará em seu texto as características constitutivas de suas posições a respeito do tema que escreveu. Com isso tem-se uma conclussão relevante: as mesmas pessoas, dependendo do lugar que ocupam nas práticas discursivas, posicionamse de forma múltipla, através de identidades diferentes e contraditórias. Fica claro que os autores assumem uma gama de identidades possíveis.

Por fim, verificou-se que há duas categorias linguísticas relevantes para este estudo: modalidade e avaliação, as quais podem servir para identificar autoria, pois a primeira diz respeito a como os autores se comprometem com eles mesmos em relação ao próprio padrão de 'verdade'; a segunda se relaciona com a noção do que é desejável ou não, bom ou ruim (avaliação).

Artigo submetido em 11/12/2008 e aceito em 24/04/2009. 
A pragmática no contexto da identificação de autoria de textos

\section{REFERÊNCIAS}

AUSTIN, J. L. How to do things with words. Oxford: Oxford University Press, 1962.

BAKHTIN, M. Estética da Criação Verbal. São Paulo: Martins Fontes, 1992.

BHABHA, H. K. The location of culture. Londres: Routledge, 1998. Tradução M. Ávila; E. L. Reis; G. R. Gonçalves. Belo Horizonte: UFMG, 1998.

BUTLER, J. Gender trouble: feminism and the subversion of identity. London: Routledge, 1990.

CHOULIARAKI, L.; FAIRCLOUGH, N. Disourse in late modernity: rethinking critical discourse analisy. Edinburgo: Edinburgh University Press, 1999.

CRYSTAL, D. A dictionary of linguistics and phonetics. In: KASPER, Gabriele. Can pragmatic competence be taught?. Disponível em: <http://www.nflrc.hawaii.edu/networks/NW06/>. Acesso em: 04 nov. 2008.

FAIRCLOUGH, N. Analysing discourse. Londres: Routledge, 2003.

GIDDENS, A. Modernidade e identidade. Rio de Janeiro: Jorge Zahar, 2002 .

GRICE, H. P. Logic and conversation. In: COLE; MORGAN, J. (Ed.). Syntax and semantics 3: speech acts. New York: Academic Press, 1975. Disponível em: <http://www.sfu.ca/ jeffpell/ Cogs300/GriceLogicConvers75.pdf >. Acesso em: 17 out. 2008.

Lógica e conversação. In: DASCAL, Marcel (Org.) Fundamentos metodológicos da linguística: pragmática: problemas, críticas, perspectivas da linguística. Campinas: Ed. do autor, 1982. V. 4
HALL, Stuart. Identidades culturais na pós-modernidade. Tradução de T. T. da Silva; G. L Louro. Rio de Janeiro: DP\&A, 2001.

A identidade cultural na pós-modernidade. 4. ed. Rio de Janeiro: DP\&A, 1992.

KOCH, I. G. V. Argumentação e Linguagem. São Paulo : Cortez, 1999.

MAINGUENEAU, D. Novas tendências em análise do discurso. Tradução de Freda Indursky; Solange Maria Ledda Gallo; Maria da Glória de Deus Vieira de Moraes. 3. ed. Campinas, SP: Unicamp, 1997.

MARCONDES, Danilo. Desfazendo mitos sobre a pragmática. Disponível em: <http://publique.rdc.puc-rio.br/revistaalceu/ media/alceu_n1_Danilo.pdf>. Acesso em: 03 nov. 2008.

MEY, Jacob. Pragmatics: an introduction. Oxford: Blackwell, 1993. Pragmatics: an introduction. Oxford: Blackwell, 2000. Concise encyclopedia of pragmatics. [S. 1]: Elsevier, 1998.

OLIVEIRA, Jair Antonio. Comunicação e educação: uma perspectiva pragmática. Disponível em: < http://www.bocc.ubi.pt/pag/ oliveira-jair-comunicacao-educacao.pdf>. Acesso em: 07 nov. 2008.

SIGNORINI, I. Lingua(gem) e identidade. Campinas, SP: Mercado das Letras, 1998.

SILVA, T. T. da (Org.). Identidade e diferença: a perspectiva dos estudos culturais. Rio de Janeiro: Vozes, 2000. 